\title{
Development from birth to sexual maturity in a semi-free- ranging colony of mandrills (Mandrillus sphinx) in Gabon
}

\author{
E. J. Wickings and A. F. Dixson \\ Centre International de Recherches Médicales de Franceville, BP 769, Franceville, Gabon
}

\begin{abstract}
Summary. This report presents information collected over 7 years (1983-1990) in Gabon, on a breeding group of 14 , increasing to 45 , mandrills maintained in a rainforest enclosure. Under these conditions, a seasonal cycle of mating (June-October) and birth (January-May) occurred. Females began to exhibit sexual skin swellings at age $2.75-4.5$ years $(3.6 \pm 0.6$ years, mean $\pm \mathrm{SD} ; n=10)$ and first delivered offspring when $3 \cdot 25-5 \cdot 5$ years old $(4 \cdot 4 \pm 0 \cdot 8$ years; $n=9)$. Gestation periods ranged from 152 to 176 days ( $167 \pm 9$ days; $n=6$ accurately dated pregnancies) and interbirth intervals from 11 to 15 months $(12 \cdot 4 \pm 1 \cdot 3$ months; $n=15)$. Females could reproduce 2 years before attaining adult body weight $(10-15 \mathrm{~kg})$ and complete dental eruption by $5 \cdot 0-5 \cdot 5$ years. Males, by contrast, developed more slowly, reaching adult body weight ( 30 $35 \mathrm{~kg}$ ) and testicular volume (volume of left testis: $25-30 \mathrm{ml}$ ) at 8 years. Consistently high circulating testosterone concentrations $\left(8 \cdot 17 \pm 2.0 \mathrm{ng} \mathrm{ml}^{-1}\right)$ could be measured by 9 years of age. Fully developed males exhibited fatting of the rump and flanks, as well as striking sexual skin coloration and an active sternal cutaneous gland; little expression of these features was evident during pubertal development. Marked individual age differences occurred with regard to the onset and complete development of these features, suggesting possible interactions between social environment and physical maturation.
\end{abstract}

Keywords: mandrill; puberty; testicular function; interbirth interval; sex characters

\section{Introduction}

The mandrill (Cercopithecinae; Mandrillus sphinx) is the largest Old World monkey, occupying a unique habitat in the tropical rainforests of western central Africa. It is a forest-dwelling, semiarboreal primate, perhaps filling the equivalent ecological niche to the baboon species found in savanna areas of eastern Africa. Its range is delineated by the Sanaga river (Cameroon) to the north, the Ivindo and Ogooue rivers (Gabon) to the east and by the Zaire basin to the south (Harrison, 1988). Because of their timid nature and the dense vegetation of their forest habitat, mandrills are very difficult animals to study in the field. Studies have yielded information on the social organization and ecology of mandrills (Sabater Pi, 1972; Jouventin, 1975; Hoshino et al., 1984; Lahm, 1986; Harrison, 1988), but there are few published data on growth and development of mandrills (Hill, 1970). No systematic investigation has been carried out, despite mandrills being held in many zoological collections, where they provide striking exhibits because of the sexual dimorphism and the brilliant coloration of the male.

The Centre International de Recherches Médicales de Franceville (CIRMF) has an established mandrill colony within a natural rainforest enclosure, which allows observation of the animals in a seminatural environment, with the possibility of restraint for examining individuals on a regular basis. The detailed records kept of this colony since its foundation provide unique data on the development (somatic and sexual) of mandrills from birth to reproductive maturity. 


\section{Materials and Methods}

\section{Animals and handling procedures}

The colony was originally founded in 1983/84 with 14 founder members (six males aged $2-4$ years, and eight females aged 1-6 years, according to retrospective analysis of their dental status on arrival). All other additions to the colony have occurred through births; some individuals were removed for reasons of incompatibility. At the time of data retrieval (1990), there were 45 mandrills in the enclosure, 17 males (2-11 years), 16 females (3-13 years) and 12 infants and juveniles ( $<2$ years) of undetermined sex.

The enclosure comprised 6 ha of natural rainforest, with a small, enclosed, concreted area for feeding and capturing the animals. Seasonal fruit and vegetables were supplied daily to supplement the natural diet provided by foraging; water and standard monkey pellets (Extralabo Croquettes Singes: Pietremont, France) were available ad libitum. Gabon is situated on the equator, where annual rainfall averages $2.5 \mathrm{~m}$ and minimum temperatures are approximately $25^{\circ} \mathrm{C}$. There are four distinct seasons: major rainy season, February-June; major dry season, June-September; short rainy season, September-December; short dry season, December-February.

All mandrills within the enclosure were captured at least once a year for a routine health check; otherwise they were not interfered with unnecessarily. Adult males were anaesthetized with ketamine hydrochloride (Imalgène: Rhone-Merieux, France; $10 \mathrm{mg} \mathrm{kg} \mathrm{kg}^{-1}$ body weight) with added acepromazine (Calmivet: Vétoquinol SA, Lure, France; $50 \mathrm{mg} \mathrm{kg}^{-1}$ body weight) from a propelled syringe fired from a blowpipe (Telinject: Roemerberg, Germany); adult females and all younger mandrills were anaesthetized by intramuscular injection with the same preparation. Animals were transported back to the Primate Centre for weighing, dental inspection, blood sampling for haematological and clinical chemical analyses, assessment of reproductive status (dimensions of the left testis in males; gynaecological examination for detection of pregnancy in females). Testicular volumes ( $v$ ) were calculated using the formula assuming a regular ellipsoid:

$$
v=\frac{\pi w^{2} l}{6}
$$

where $w$ is the width and $l$ is the length of the testis. During the most recent capture in January 1990, overall body length from the tip of the muzzle to the base of the tail was measured in all male and in some adult female animals. Facial dimensions were measured (length and width of the muzzle and the convexity of the bony, fusiform ridges that flank the central nasal ridge) and the development of the secondary sexual characteristics (facial and rump coloration and the activity of the sternal secretory gland; Hill, 1970) was assessed.

Female mandrills show a distinct season of sexual skin swellings between June and October and mating is largely restricted to this period and to the time of maximal tumescence in each cycle (A. F. Dixson \& E. J. Wickings, unpublished observations). Pregnancy lasts approximately 170 days in the mandrill (Carman, 1979), hence daily surveillance from the time of expected delivery ensured that the date of birth of infants is known to within 2-3 days. The first occurrence of sexual swellings in young females was noted, but was not documented systematically in all cases.

\section{Testosterone assay}

Testosterone was measured by enzymeimmunoassay using commercially available reagents (Serozyme: Serono Diagnostic, Rungis, France), after ether extraction of the plasma. All samples taken annually between 1983 and 1990 for each individual male were assayed at the same time. The limit of detection was $4.2 \mathrm{pg}$ per tube, the intra- and interassay variability was $6 \cdot 2 \%$ and $11 \cdot 4 \%$, respectively.

\section{Statistics}

Data were analysed by nonparametric Mann-Whitney U-test and parametric ANOvA and unpaired $t$-tests, depending on the normality of distribution of the data.

\section{Results}

\section{Dentition}

The first teeth to erupt were the decidual incisors, which were seen at or shortly after birth; only one of seven neonates had two upper incisors at birth. Complete complements of decidual teeth $\left(\frac{2}{2}\right.$ incisors $(\mathrm{I}), \frac{1}{1}$ canine $(\mathrm{C}), \frac{2}{2}$ premolars $(\mathrm{P})$; total $=20$ teeth) were present in all females and in 
six of the nine males available for study by the end of the first year of life (Table 1) and remained in position for approximately 1 to 1.5 years. The first permanent teeth (first molar, $\mathbf{M}_{1}$ ) appeared on average 3 months earlier in females than in males, and all further replacement of decidual teeth occurred first in females who completed the process at least a year before the two males for whom data are available. A complete set of permanent teeth comprised $\mathrm{I}: \frac{2}{2}, \mathrm{C}: \frac{1}{1}, \mathrm{M}: \frac{3}{3}=32$ teeth. Considerable sexual dimorphism is exhibited in the length of the permanent canine teeth in the mandrill. Female canines achieved final length of $1 \mathrm{~cm}$ one to two years after eruption, but male canines continued to grow for up to 3 years, achieving an overall length of 4 to $5 \mathrm{~cm}$. In several of the adult males, evidence was found that these teeth had been chipped or broken, and hence only intact canines were measured.

Table 1. Age sequence of eruption of decidual and permanent dentition in male and female mandrills from birth to adulthood, and comparison of the length of the adult canines

\begin{tabular}{lcccr}
\hline First appearance of & Male & $n$ & Female & $n$ \\
\hline Decidual incisors (I) (weeks) & $1-3$ & 4 & birth -4 & 3 \\
Complete decidual teeth (years) & $0 \cdot 5-1 \cdot 75$ & 8 & $0 \cdot 75-1 \cdot 0$ & 9 \\
Permanent first molar (M M $_{1}$ (years) & $2 \cdot 0-2 \cdot 75$ & 7 & $1 \cdot 75-2 \cdot 5$ & 10 \\
Permanent $I_{1}$ (years) & $3 \cdot 0-3 \cdot 75$ & 6 & $3 \cdot 0$ & 3 \\
Permanent $I_{12}$ and $M_{12}$ (years) & $4 \cdot 0-4 \cdot 75$ & 3 & $3 \cdot 0-3 \cdot 5$ & 4 \\
Complete permanent dentition & $6 \cdot 5$ & 2 & $5 \cdot 25-5 \cdot 5$ & 3 \\
$\quad$ (years) & & & & \\
$\quad$ Length of adult upper canines (cm; & $4 \cdot 5 \pm 0 \cdot 1$ & 5 & $0 \cdot 96 \pm 0.04$ & 10 \\
$\quad$ mean \pm SEM) & & & & \\
\hline
\end{tabular}

$n$ : Number of observations.

The age ranges in Table 1 have been collated from all animals for whom the date of birth was known to within 2 or 3 days, and these six stages of development were then used to judge the age of animals arriving at CIRMF with unknown dates of birth.

\section{Somatic development}

There was no difference in birth weights between male and female infants (Fig. 1), but, by the age of 2 years, males were significantly heavier than females $(P<0.013)$. Two distinct growth rates were identified for males, the first from birth to 2 years, followed by a faster, pubertal spurt until reaching adult weights of approximately $35 \mathrm{~kg}$ at 8 years. In males, there was an average weight gain of $2.25 \mathrm{~kg} \mathrm{year}^{-1}$ for the first two years, increasing to $5.1 \mathrm{~kg} \mathrm{year}^{-1}$ during rapid growth. The most sustained growing period was between 5 and 7 years. In contrast, females grew at an approximately constant rate until completing somatic development at about 5 years, gaining approximately $1.85 \mathrm{~kg} \mathrm{year}^{-1}$ throughout this period, and they continued to gain weight slowly over the next 6 years of life, at $0.71 \mathrm{~kg}$ year $^{-1}$. The difference in adult body weights (males: $30-35 \mathrm{~kg}$ versus females: $10-15 \mathrm{~kg}$ ) and nose-rump length (males: $75-80 \mathrm{~cm}$ versus females: $55-60 \mathrm{~cm}$ ) between the two sexes reveals the extent of sexual dimorphism in this species (Fig. 2).

Little variation was seen in body weights of female mandrills for a given age, and hence this parameter could also be used for assessing age during development. Using the average body weights for the nine females of known date of birth a mean growth profile $( \pm 2 \mathrm{SD})$ was defined, from which the ages of females of unknown dates of birth were extrapolated. Comparing the ages of females assessed by body weight with those assessed from their dental records the mean discrepancy was 3 months. Such an analysis was not possible for the male mandrills, as a much greater variability was evident in animals of known birthdate throughout their active growing phase. 


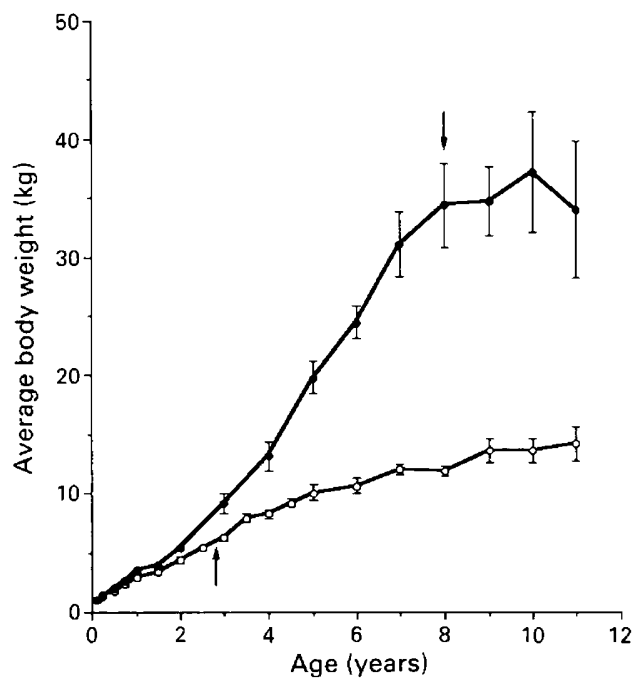

Fig. 1. Age-related weight gain (mean \pm SEM) in male $(\odot)$ and female $(O)$ mandrills from birth to adulthood; arrows indicate when mandrills of each sex attain sexual maturity.

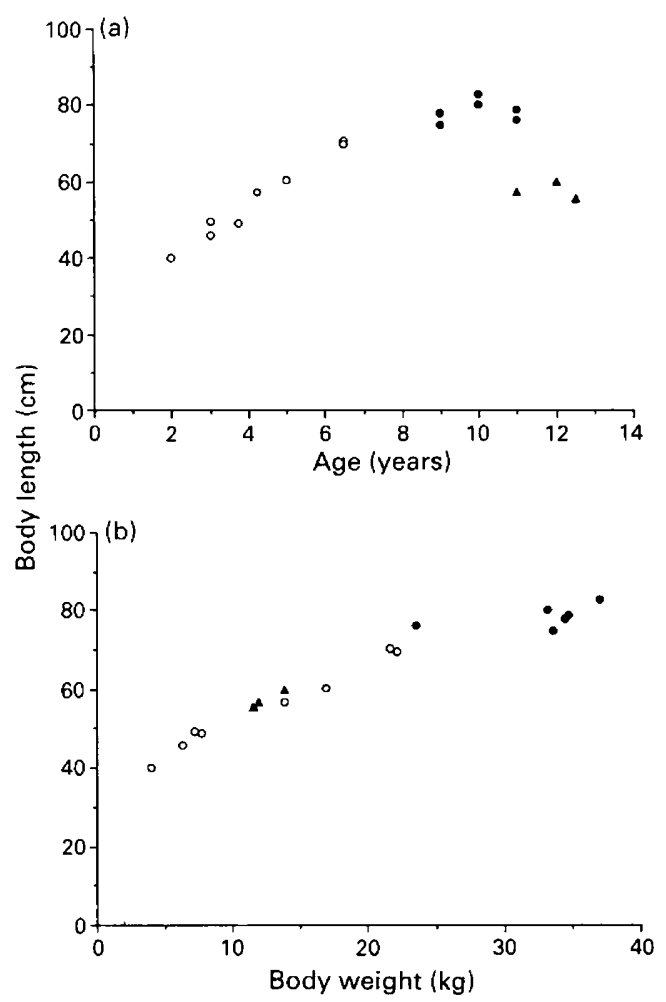

Fig. 2. Body length (tip of the nose to the base of the tail) as a function of (a) age and (b) body weight in six adult male $(\boldsymbol{O})$, eight juvenile male $(O)$ and three adult female $(\boldsymbol{\Delta})$ mandrills. 

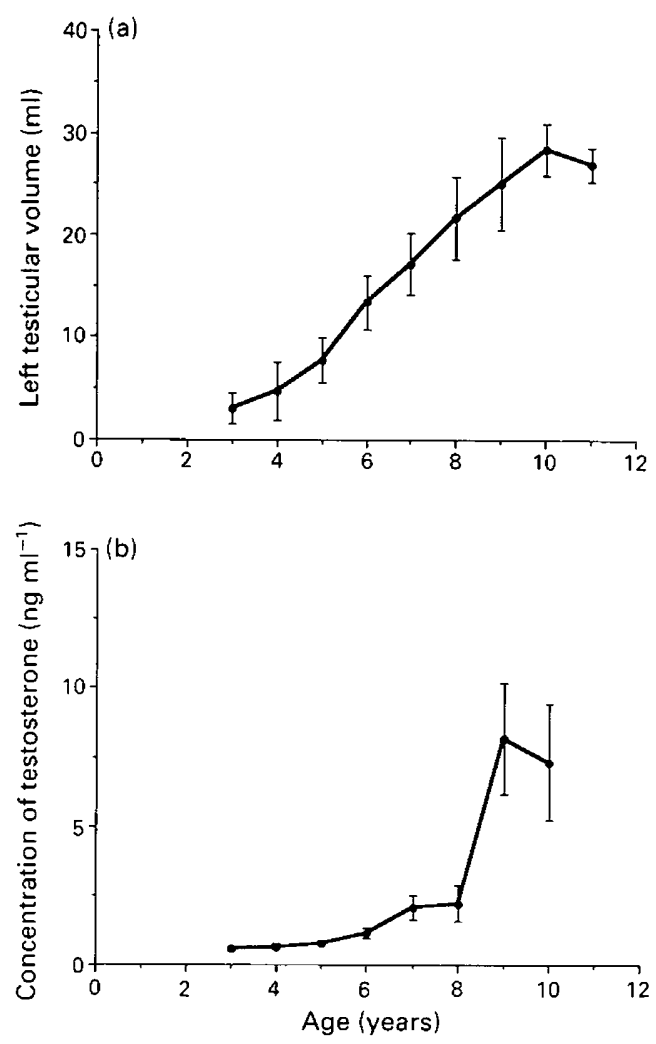

Fig. 3. Age-related development of (a) testicular volume (calculated from measurements of left testis) and (b) serum testosterone concentrations (mean \pm SEM) in mandrills.

\section{Sexual development}

Females. First full sexual skin tumescences involving the vulval and perianal regions were seen in females between the ages of 2.75 and 4.5 years $(3.6 \pm 0.6$ year, average $\pm \mathrm{SD}, n=10)$; these swellings were attractive to males who made visual and olfactory inspections of them, and these inspections were followed by ejaculatory mounts. Smaller swellings encompassing only the vaginal area were seen in two adolescent females aged 2.75 years during the 1989 and 1990 breeding seasons, and, although males mounted these individuals, no intromission was observed. Presumably these first cycles can be ovulatory, since five females delivered their first infants between the ages of 3.25 and 3.70 years, after their first season of sexual skin tumescence. The average age at first birth was 4.4 years (SD 0.8 year, range $3.25-5.5$ years, $n=10$ ), i.e. most females had given birth to one infant before attaining somatic maturity, as judged by body weight and dentition $(5 \cdot 0-5 \cdot 5$ years). The duration of pregnancy in six mandrills was timed from the day of breakdown of sexual skin tumescence to the day of delivery, resulting in an average gestation period of $167 \pm 9$ days (mean $\pm \mathrm{SD}$; range 152-176 days); all six infants were healthy.

Once the females became reproductively active, they showed a marked seasonality of ovarian cycles, conceptions and births, with interbirth intervals of between 11 and 15 months $(12.4 \pm 1 \cdot 3$ months $\pm \mathrm{SD}, n=15$ ). Twenty-five out of 26 births from 1985 to 1990 occurred between January and May (corresponding to the major rainy season in Gabon), and, by subtracting a gestation period of 167 days ( 5.4 months), this would place the main period of fertility and conceptions in the colony between June and October (major dry season).

Males. Testicular descent occurred at an average age of $3 \cdot 2 \pm 1 \cdot 1$ years (mean $\pm \mathrm{SD}$; range $2 \cdot 0$ 4.5 years) in seven juvenile males of known dates of birth. At the time of descent and for the first 

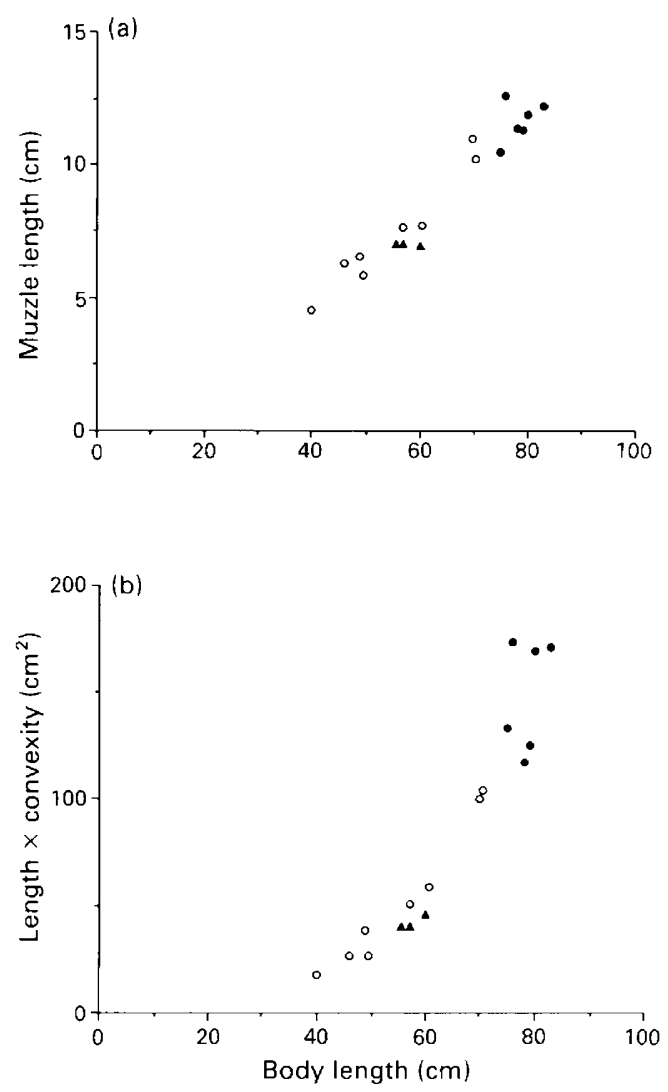

Fig. 4. Facial dimensions: (a) length of muzzle and (b) product of length of muzzle and convexity of the two fusiform ridges in six adult male ( $)$, eight juvenile male $(O)$ and three adult female $(\boldsymbol{\Delta})$ mandrills, in relation to body length.

year thereafter, the testes remained small (volume of left testis: $3.0 \pm 1.6 \mathrm{ml}$; mean \pm SEM; $n=6$ ). Thereafter, testicular volume increased linearly throughout the pubertal growth phase, until attaining adult volumes of $25-30 \mathrm{ml}$ (Fig. 3a). Serum testosterone concentrations showed a slight increase throughout puberty but generally remained low $\left(0.57 \pm 0.06 \mathrm{ng} \mathrm{ml}^{-1}\right.$ at 3 years increasing to $2 \cdot 21 \pm 0.67 \mathrm{ng} \mathrm{ml}^{-1}$ at 7 years; mean $\pm \mathrm{SEM}$ ); after the age of 8 years, testosterone concentrations then increased markedly to reach adult levels $\left(8 \cdot 17 \pm 2.00 \mathrm{ng} \mathrm{ml}^{-1}\right)$ a year later (Fig. 3b).

Fully developed secondary sexual characteristics (fatted appearance, brilliant coloration on the rump (red, blue and mauve) and scrotal area and penis (red and mauve), prominent blue fusiform nasal ridges flanking the central red nasal stripe, golden mane with active sternal gland) were seen only in adult male mandrills. The increase in body weight seen in adult animals once they had stopped growing longitudinally resulted in the fatted phenomenon, where fat accumulated around the rump and flanks, and the scrotal sack became pendulous. Qualitative observations made throughout one year indicated that adult males remained fatted, the testes were prominent and scrotal, and that sexual skin coloration was maintained during the period of reproductive quiescence in female mandrills, i.e. the male does not appear to show seasonality in his reproductive function. During puberty, the length (and width; data not shown) of the muzzle grew in proportion to body size (Fig. 4a), but the increase in convexity of the fusiform ridges in adult mandrills was larger than predicted from the average growth curve. Taking the product of muzzle length and convexity as an index of the development of the facial characteristics of the adult male, this parameter also increased disproportionately in adult males, following an approximately linear increase 
during puberty (Fig. 4b). Adolescent and subadult males resembled adult females in the extent of their facial development and coloration. The sternal gland was evident in all males aged 3 years or older; the skin pores were enlarged and the covering hairs lengthened and coarsened and became chestnut in colour, compared with the surrounding areas. Active secretion from the gland was seen only in males that were more than 6 years old.

\section{Discussion}

The mandrill is phylogenetically sufficiently distinct from its savanna-dwelling relative the baboon (Papio spp.) to merit a separate genus, but many aspects of its anatomy and physiology are similar enough to warrant comparison of the mandrill with the better characterized species of baboons and macaques. However, many data available in the literature on development and reproduction in mandrills are incomplete. Estimates on the length of gestation vary from 170 days (Carman, 1979), similar to baboons and macaques (Napier \& Napier, 1967), to 220-270 days (Asdell, 1964; Hill, 1970). From the records of the CIRMF colony kept over its 7 year history, gestation lasted approximately 167 days in the six instances where pregnancy could be timed accurately.

Mandrill infants are well developed at birth and, as soon as the decidual teeth begin to develop, they start mimicking adult feeding habits, taking food from their mother's mouth and foraging in the undergrowth. Physical development is rapid during infancy, and at 2 years the sexual dimorphism in body size so apparent in the adult first manifests itself. However, pubertal males continue to resemble adult female mandrills in size and appearance until they attain adulthood, when the secondary sexual adornments characteristic of this species (the startling red-blue rump coloration and the red penis mimicked by the red stripe on the nose flanked by the two prominent blue fusiform ridges) finally develop. The blue coloration is a permanent, melanin-derived dermal pigmentation seen in some Cercopithecus species; the red sex skin is similar to that seen round the perineal area in the rhesus monkey, which has been shown to be androgen dependent (Vandenbergh, 1965). In the closely related, but geographically separate, drill (Mandrillus leucophaeus), Zuckerman \& Parkes (1939, quoted by Hill, 1970) demonstrated that the red, but not the blue, sex skin coloration was testosterone dependent. Little change was seen in basal testosterone concentrations during puberty in the mandrill, which is in direct contrast to the continual increases in testosterone found in other Old World monkey species (Rose et al., 1978; Mann et al., 1983; Brady et al., 1985; MeusyDessolle et al., 1985). The abrupt development of the secondary sexual characteristics occurred in the mandrills only after testosterone levels had attained adult values. Testosterone concentrations of adult mandrills were lower in those males showing less well-developed secondary sexual adornments (Wickings \& Dixson, 1990).

One of the characteristics of the adult male mandrill is his stocky appearance. We have chosen to describe this appearance as 'fatted' since body weights do not differ significantly from less welldeveloped males and the distribution of weight apparently shifts to the rump and flank areas. These regions are sparsely haired and hence the 'fatted' appearance is even more marked. However, this is not the seasonal 'fatting' seen in the New World squirrel monkeys (Saimiri sciureus; DuMond \& Hutchinson, 1967), as adult mandrills retain this appearance throughout the year once secondary sexual characteristics become fully developed. Testicular function in male mandrills does not appear to be seasonal in character: no qualitative differences in testicular size were apparent. In reproductively quiescent rhesus monkeys, testicular volume is reduced to $30-50 \%$ of values found during the breeding season, and the red perineal sex skin colour fades (Sade, 1964; Wickings \& Nieschlag, 1980). All testosterone values reported here correspond to concentrations measured during the period of female reproductive quiescence (seen even in nonlactating females) after the annual birth season.

One feature that distinguishes the male mandrill and the drill from baboon species is the existence of a sternal scent gland in the adult male, which is absent in all other Old World monkeys (Hill, 1970). The position of the gland is marked by a tuft of long bristly hairs, which have a deeper 
chestnut colour than the surrounding lighter ventral hairs. The glandular appearance of the skin is evident in prepubertal males, before secretory activity commences in midpuberty. The role of the scent gland is unknown in freeranging mandrills. In the CIRMF colony, adult males have been observed to rub the chest area against tree trunks, leaving a damp patch with a musky odour (Feistner, 1990). Whether this marking serves to delineate home-range areas or as a means of passing on pheromonal cues between group-individuals or between groups remains to be elucidated.

Testicular volume reaches adult proportions at 8 years of age, comparatively late in life compared with male baboons and macaques, which attain sexual maturity some two to three years earlier (Napier \& Napier, 1967). To date, no information is available on sperm production in mandrills, but adult males deposit a visible semen plug in the vagina of females. Observations of the mandrill group during the breeding season revealed that all adult males deposited semen plugs; no copulatory activity was seen during the nonbreeding season, in the absence of receptive females. It is difficult to assess whether ejaculatory activity commences during puberty as hierarchical interactions between male mandrills reduce access to females for subordinate and younger males (A. F. Dixson \& E. J. Wickings, unpublished observations). The earliest ejaculatory mounts within the CIRMF colony were recorded for two males aged 4.75 and 5.5 years, at a time when testicular development was not well pronounced in either male.

Puberty in the male is marked by the descent of the testes into the scrotum at the age of approximately 3 years, and testicular growth then continues in a linear fashion over an extended period of 5-6 years. This period of growth is similar to that seen in boys and chimpanzees (Marshall, 1978; Kraemer et al., 1982), but is considerably longer than that in other Old World monkey species where testicular growth is complete by the age of 5 years (Copeland et al., 1981; Steiner \& Bremmer, 1981). In contrast to the linear increase in testicular size, circulating testosterone concentrations were raised only in adult animals. However, the single, annual sampling regimen makes no attempt to accommodate the short-term and nocturnal fluctuations in testosterone that characterize puberty in other primates (for overview, see Plant, 1988). Hence gonadotrophin-releasing hormone $(\mathrm{GnRH})$ stimulation tests $(100 \mu \mathrm{g}$, i.v.) were used to chart the changes in testicular endocrine capacity commensurate with maturation of the hypothalamic-(pituitary)-gonadal axis. Mandrills aged more than 4 years showed an increase in testosterone, indicating that the Leydig cells could respond to the challenge, even if basal testosterone secretion remained very low; testosterone responses elicited during late pubertal development were of a similar magnitude to those in the adult, despite the low basal testosterone concentrations (data not shown). These preliminary data would indicate that some endocrine maturation of the testis does occur in advance of apparent changes in basal secretion.

In contrast to the male, physical and sexual development in the female is more precocious, with full sexual maturity evident before the completion of somatic development at the age of 5 years. Animals can conceive and bear live infants as early as 3 years of age, which is considerably younger than either baboons or macaques (Napier \& Napier, 1967). Mandrills do not appear to undergo the period of adolescent infertility seen after the menarche common in other primate species (Callithrix jacchus: Abbott, 1978; Macaca mulatta: Resko et al., 1982; Papio cynocephalus: Altmann et al., 1981; Pan troglodytes: Pusey, 1980; humans: Thomson, 1976) since five of the ten conceptions documented here occurred during the first season of cyclicity of the female. Common defects associated with first ovarian cycles are insufficient, or short, luteal phases (Apter et al., 1978; Resko et al., 1982). Given the husbandry conditions of the CIRMF colony, it was not possible to investigate the endocrine changes associated with commencement of ovarian cycles; hence all data on female maturation are based on observations of sexual tumescences, which in all other primates are oestrogen dependent (Carlisle et al., 1981; Dixson, 1983). Sexual swellings in adolescent females are smaller than those in adult mandrills, which may be the result of lower oestrogen production in the pubertal ovary, or reduced sensitivity of the sex skin fibroblasts to oestrogen during the early stages of stimulation. A similar trend in the size of sexual skin swellings with successive annual mating 
seasons has been observed for the talapoin monkey (Miopithecus talapoin; Rowell, 1977), rhesus macaques (Van Wagenen, 1952), baboons (Scott, 1979) and chimpanzees (Coe et al., 1979). One factor contributing to the precocious sexual development of female mandrills may be the additional provisioning of the colony. Studies comparing freeranging populations with captive groups or provisioned, freeranging animals have shown that increased calorific intake plays an important role in the rate of maturation of primates (Altmann et al., 1981; Mori, 1979), just as food deprivation has the reverse effect (Dubey et al., 1986). However, the difference in rates of maturation between male and female mandrills cannot be explained in terms of food intake, since the same diet was available to all members of the colony.

In summary, growth and development characteristics of the mandrill indicate that the female develops very much earlier than the male, in whom social interactions may play an important role in the rate of development. Similarities in female sexual maturation exist among mandrills, macaques and baboons, but the male mandrill shows retarded development compared with these other species.

Thanks are due to all members of staff of the Primate Centre who were involved in the collection of data for this study under the direction of R. W. Cooper (Director of the Primate Centre, CIRMF, 1980 to 1988) and to I. Orbell for maintaining the detailed files on each animal; we also thank N. Orbell, without whose help the captures would not have been effected. CIRMF is financed jointly by the Gabonese government (70\%) and Elf Gabon.

\section{References}

Abbott, D.H. (1978) The physical, hormonal and behavioural development of the common marmoset, Callithrix jacchus. In The Biology and Behaviour of Marmosets, pp. 99-106. Eds H. Rothe, H. Wolters \& J. Hearn. Eigenverlag, Goettingen.

Altmann, J., Altmann, S. \& Hausfater, G. (1981) Physical maturation and age estimates of yellow baboons in Amboseli National Park, Kenya. American Journal of Primatology 1, 389-399.

Apter, D., Viinikka, L. \& Vihko, R. (1978) Hormonal pattern of adolescent menstrual cycles. Journal of Clinical and Endocrine Metabolism 47, 944-954.

Asdell, S.A. (1964) Patterns of Mammalian Reproduction. Constable \& Co., London.

Brady, A.G., Koritnik, D.R. \& Stevens, S.W. (1985) Hormonal responses to gonadotropin releasing hormone during testicular development in male African green monkeys. Journal of Medical Primatology 14, 293-304.

Carlisle, K.S., Brenner, R.M. \& Montagna, W. (1981) Hormonal regulation of sex skin in Macaca nemestrina. Biology of Reproduction 25, 1053-1063.

Carman, M. (1979) The gestation and rearing periods of the mandrill at the London Zoo. International Zoo Yearbook 19, 159-160.

Coe, C.L., Connolly, A.C., Kraemer, H.C. \& Levine, S. (1979) Reproductive development and behaviour of captive female chimpanzees. Primates 20, 571-582.

Copeland, K.C., Kuehl, T.J., Reyes, P. \& Castracane, V.D. (1981) The baboon as a model for puberty: growth, testis size, plasma testosterone and somatomedin-C. Pediatric Research 15, 1547 (Abstract 56).

Dixson, A.F. (1983) Observations on the evolution and behavioral significance of 'sexual skin' in female primates. Advances in Study of Behavior 13, 63-106.

Dubey, A.K., Cameron, J.L., Steiner, R.A. \& Plant, T.M.
(1986) Inhibition of gonadotropin secretion in castrated male rhesus monkeys (Macaca mulatta) induced by dietary restriction: analogy with the prepubertal hiatus of gonadotropin release. Endocrinology 118, 518-525.

DuMond, F.V. \& Hutchinson, T.C. (1967) Squirrel monkey reproduction: the 'fatted' male phenomenon and seasonal spermatogenesis. Science 158, 1067-1070.

Feistner, A.T.C. (1990) Scent-marking in mandrills (Mandrillus sphinx). Proceedings of the XIIIth Congress, International Primatological Society, Japan, p. 21 Abstract.

Harrison, M.J.S. (1988) The mandrill in Gabon's rain forest-ecology, distribution and status. Oryx 22, 218-228.

Hill, W.C.O. (1970) Primates: Comparative Anatomy and Taxonomy, vol. VIII Cynopithecinae. The University Press, Edinburgh.

Hoshino, J., Mori, A., Kudo, H. \& Kawai, M. (1984) Preliminary report on the grouping of mandrills (Mandrillus sphinx) in Cameroon. Primates 25, 295-307.

Jouventin, P. (1975) Observations sur la socio-ecologie du mandrill. La Terre et la Vie 29, 493-532.

Kraemer, H.C., Horvat, J.R., Doering, C. \& McGinnis, R.R. (1982) Male chimpanzee development focusing on adolescence: integration of behavioral with physiological changes. Primates 23, 393-405.

Lahm, S.A. (1986) Diet and habitat preference of Mandrillus sphinx in Gabon: implications of foraging strategy. American Journal of Primatology 11, 9-26.

Mann, D.R., Castracane, V.D., McLaughlin, F., Gould, K.G. \& Collins, D.C. (1983) Development patterns of serum luteinizing hormone, gonadal and adrenal steroids in the sooty mangabey (Cercocebus atys). Biology of Reproduction 28, 279-284. 
Marshall, W.A. (1978) Puberty. In Human Growth, vol. 2: Postnatal Growth, pp. 141-181. Eds F. Falkner \& J. M. Tanner. Plenum Press, New York.

Meusy-Dessolle, N. \& Dang, D.C. (1985) Plasma concentrations of testosterone, dihydrotestosterone, $\Delta^{4}$-androstenedione, dehydroepiandrosterone and oestradiol-17 $\beta$ in the crab-eating monkey (Macaca fascicularis) from birth to adulthood. Journal of Reproduction and Fertility 74, 347-359.

Mori, A. (1979) Analysis of population changes by measurement of body weight in the Koshima troop of Japanese monkeys. Primates 20, 371-398.

Napier, J.R. \& Napier, P.H. (1967) A Handbook of Living Primates. Academic Press, London.

Plant, T.M. (1988) Puberty in primates. In The Physiology of Reproduction, pp. 1763 1788. Eds E. Knobil \& J. Neill. Raven Press, New York.

Pusey, A.E. (1980) Inbreeding avoidance in chimpanzees. Animal Behaviour 28, 543-552.

Resko, J.A., Goy, R.W., Robinson, J.A. \& Norman, R.L. (1982) The pubescent monkey: some characteristics of the menstrual cycle. Biology of Reproduction 27, 354-361.

Rose, R.M., Bernstein, I.S., Gordon, T.P. \& Lindsley, J.G. (1978) Changes in testosterone and behaviour in adolescence in the male rhesus monkey. Psychosomatic Medicine 40, 60-70.

Rowell, T.E. (1977) Variation in age at puberty in monkeys. Folia Primatologica 27, $284-290$.

Sabater Pi, J. (1972) Contribution to the ecology of Mandrillus sphinx Linnaeus 1758 of Rio Muni. Folia Primatologica 17, 304-319.
Sade, D.S. (1964) Seasonal cycle in size of testes of free-ranging Macaca mulatta. Folia Primatologica 2, $171-180$.

Scott, L.M. (1979) Sexual swellings and reproduction in adolescent female baboons. American Journal of Physical Anthropology 50, 479-480.

Steiner, R.A. \& Bremner, W.J. (1981) Endocrine correlates of sexual development in the male monkey, Macaca fascicularis. Endocrinology 109, 914919.

Thomson, A.M. (1976) Pregnancy in adolescence. In Nutrient Requirements in Adolescence, pp. 245-256. Eds J. I. McKigney \& H. N. Munro. Massachusetts Institute of Technology Press, Cambridge, MA.

Vandenbergh, J.G. (1965) Hormonal basis of sex skin in male rhesus monkeys. General and Comparative Endocrinology 5, 31-34.

Van Wagenen, G. (1952) Age at menarche of the laboratory rhesus monkey. Anatomical Record 112,436.

Wickings, E.J. \& Dixson, A.F. (1990) Dominance rank, testicular function and secondary sexual characteristics in the male mandrill. Proceedings of the XIIIth Congress, International Primatological Society, Japan, p. 104 (Abstract).

Wickings, E.J. \& Nieschlag, E. (1980) Seasonality in endocrine and exocrine testicular function of the adult rhesus monkey (Macaca mulatta) maintained in a controlled laboratory environment. International Journal of Andrology 3, 87-104.

Zuckerman, S. \& Parkes, A.S. (1939) Observations on secondary sexual characters in monkeys. Journal of Endocrinology 1, 430439.

Received 7 February 1991 